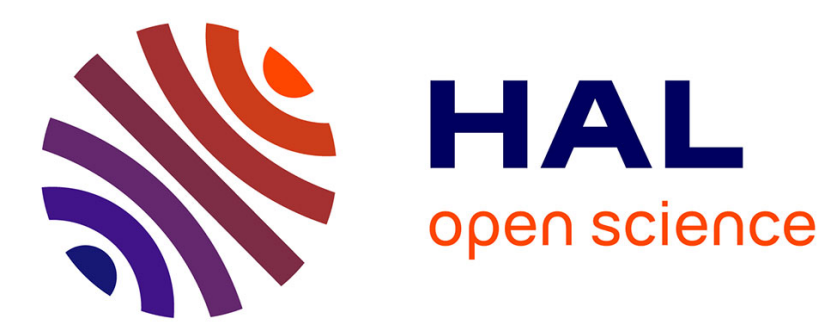

\title{
Two-dimensional systems as mimetic membranes
}

\author{
G. Gabrielli, G. Caminati, M. Puggelli, A. Gilardoni, E. Margheri
}

\section{To cite this version:}

G. Gabrielli, G. Caminati, M. Puggelli, A. Gilardoni, E. Margheri. Two-dimensional systems as mimetic membranes. Journal de Physique IV Proceedings, 1993, 03 (C1), pp.C1-279-C1-295. 10.1051/jp4:1993124 . jpa-00251567

\section{HAL Id: jpa-00251567 https://hal.science/jpa-00251567}

Submitted on 1 Jan 1993

HAL is a multi-disciplinary open access archive for the deposit and dissemination of scientific research documents, whether they are published or not. The documents may come from teaching and research institutions in France or abroad, or from public or private research centers.
L'archive ouverte pluridisciplinaire HAL, est destinée au dépôt et à la diffusion de documents scientifiques de niveau recherche, publiés ou non, émanant des établissements d'enseignement et de recherche français ou étrangers, des laboratoires publics ou privés. 


\title{
Two-dimensional systems as mimetic membranes
}

\author{
G. GABRIELLI, G. CAMINATI, M. PUGGELLI, A. GILARDONI and E. MARGHERI
}

Dipartimento di Chimica, Via G. Capponi 9, 50121 Firenze, Italy

\begin{abstract}
Monolayers and bilayers are useful models of natural membranes, in this paper we report some investigations either on membrane components or their model analogs, in two-dimensional state.

In particular we studied mixed monolayers of two polypeptides to deduce the interfacial orientation and the bidimensional miscibility of the two macromolecules. The properties of lipids in monolayers, Black Lipid Membranes (BLM) and vesicles were then compared. We obtained the conditions of molecular structure and of interfacial distribution for the formation and the stability of each model system. We also modeled photoprocesses occurring in natural membranes studying charge transfer in mono and multilayers between an excited donor implanted in the lipid portion of the system and an appropriate water soluble acceptor. Finally we describe the construction of a mimetic membrane containing an ioncarrier, namely valinomycin, by means of Langmuir-Blodgett technique that proved to be selective to potassium ions.
\end{abstract}

\section{RÉSUMÉ}

En considérant que le monocouches et bicouches sont des modéles de membrane trés utiles, on report des investigations menées soit sur des composants modéles soit sur des constituants des membranes elles-même. En particulier on etudie des monocouches melange de deux polypeptides et l'on déduit leur orientation à l'interface ainsi que leur miscibilité bidimensionnelle.

On compare ensuite le proprietés des lipides dans le monocouches, le BLM et le vésicules et l'on deduit les conditions de structure moléculaire et de distribution interfasale nécessaires à la formation et à la stabilité de chaque systeme bidimensionnel.

On étudie aussi le processes de transferement de charge et de masse dans le monocouches et multicouches. Enfin on reporte la réalization d'une membrane mimetique contenante un transportateur ionique (Valinomicine) par le moyen de multicouches de L-B, qui se révéle selective aux ions $\mathrm{K}^{+}$. 


\section{INTRODUCTION}

The surfaces of liquids can be considered as not independent portions of matter, because although they are highly structured and have peculiar physico-chemical properties, they are correlated to the contiguous bulk phases.

In this review we present the results we obtained studying some bidimensional systems at liquid interfaces, which can act as mimetic membranes.

In fact natural membranes themselves are two-dimensional systems, consisting [1] of a lipid bilayer in which the other components, most of all proteins, are deeply inserted or linked.

That is the reason why monolayers and flat or curved bilayers are the most representative models of biological membranes, above all if they are constituted by the same components of natural membranes or have similar properties.

These models not only represent an useful tool to understand the structure and functions of natural membranes, but they can also be designed for the construction of mimetic membranes that reproduce some of the very extraordinary properties of the natural ones.

The research has been developed along the following main directions:

1) Study of monolayers at the liquid-air interface, being these systems the simplest model of natural membranes which can give information about the molecular distribution at the interface and about the interactions among membrane components.

2) Comparison among different model systems in order to establish the actual similarity and feasibility of the various supramolecular structures.

3) Study in mono and muitilayers of the photoprocesses occurring in natural membranes, that is to say transport of energy or charge.

4) Accomplishment of a mimetic membrane for selective $K^{+}$ion transport by means of the LangmuirBlodgett technique.

For each of the above mentioned steps only some representative results are shown, chosen among all the ones we have obtained during our research. From the body of the presented results it is possible to draw some general considerations about this subject. A wide number of references is also given.

\section{MATERIALS AND METHODS}

\section{Materials}

The following materials have been used as monolayer or different membrane model components: Poly-L-alanine (PLA) supplied by ICN Pharmaceuticals with an average molecular weight of 63,000 determined in the two-dimensional phase by extrapolation of the linear portion of the $\pi \mathrm{A}-\mathrm{A}$ isotherms in the limit of $\pi \rightarrow 0$. Poly- $\gamma$-methyl-L-glutamate (P $\gamma M G)$ supplied by Sigma GmbH, Deisenhofen, GER, with a viscosimetrically determined average molecular weight of 46,000. 1-monooleoyl-glycerol (MON) and ceramides (CER) from bovine brain were supplied by Sigma Chemie, Darmstadt, GER; the composition in carboxylic acids was previously reported [2]. Dipalmitoylphosphatidic acid (DPPA) was supplied by Aldrich and L- $\alpha$-dioleoylphosphatidylcholine (DOPC), methylviologen (MV) and valinomycin (VAL) were supplied by Sigma Chemie, Darmstadt, GER. Dioctadecyloxacyanine (OC) was prepared according to Sondermann [3]. Stearic Acid (SA)and methylstearate (MS) were obtained by C. Erba, Milano, ITALY. Different spreading solvents were used, which have been reported in previous papers together with the preparation of the spreading solutions $[2,4,12,31]$.

\section{Methods}

Measurements of surface pressure $(\pi)$ as a function of molecular areas were carried with the Langmuir 
method [5] using an apparatus and an experimental procedure already described [6]. The accuracy was determined to be $0.07 \mathrm{mN} / \mathrm{m}$ for surface pressure, $0.01 \mathrm{~m}^{2} / \mathrm{mg}$ for molecular areas and $0.05{ }^{\circ} \mathrm{C}$ for temperature. Transfer from liquid to solid support was carried out using a Joyce-Loebl model 4 and a KSV LB5000 apparatus [2,12]. The thickness of the films transferred onto solid supports was evaluated ellipsometrically [7] using an ellipsometer 43702-200E (Rudolph Research, U.S.A.), the error was estimated to be $\pm 5 \%$. Vesicles were prepared by sonication of aqueous dispersions using a Branson Sonic B12 sonicator and centrifugated using a Beckman J2-21 centrifuge [8]. To determine MIR spectra, the monolayers were transferred onto Germanium plates which were inserted into a Perkin Elmer Model 983 spectrometer.

BLM were prepared according to Mueller [9] depositing onto a hole a solution of the desired amphiphile, or of its mixtures, in a suitable solvent [2]. Electrical capacitance and resistance measurements were performed using a previously described experimental set-up [2]; the percentage error for each specific capacitance value was always lower than $1.4 \%$.

Reflection spectra of the monolayer were obtained using an apparatus previously described [10]. Fluorescence measurements at water-air interface were performed using a fiber optics set-up previously reported [11], the monolayer was excited at $365 \mathrm{~nm}$ and the emission was measured normal to the interface at $425 \mathrm{~nm}$.

The ion-selective membrane was prepared with the Langmuir-Blodgett technique transferring the monolayers on a porous membrane (polyvinylidene difluoride) using the experimental conditions reported in ref. 12. Resistance measurements were performed connecting a teflon cell described elsewhere [12] to the same apparatus employed for electrical measurements on BLM. The experimental conditions are reported in ref. 12.

\section{RESULTS AND DISCUSSION}

The two-dimensional systems we studied as model of biological membranes are shown schematically in figure 1 .

MONOLAYERS
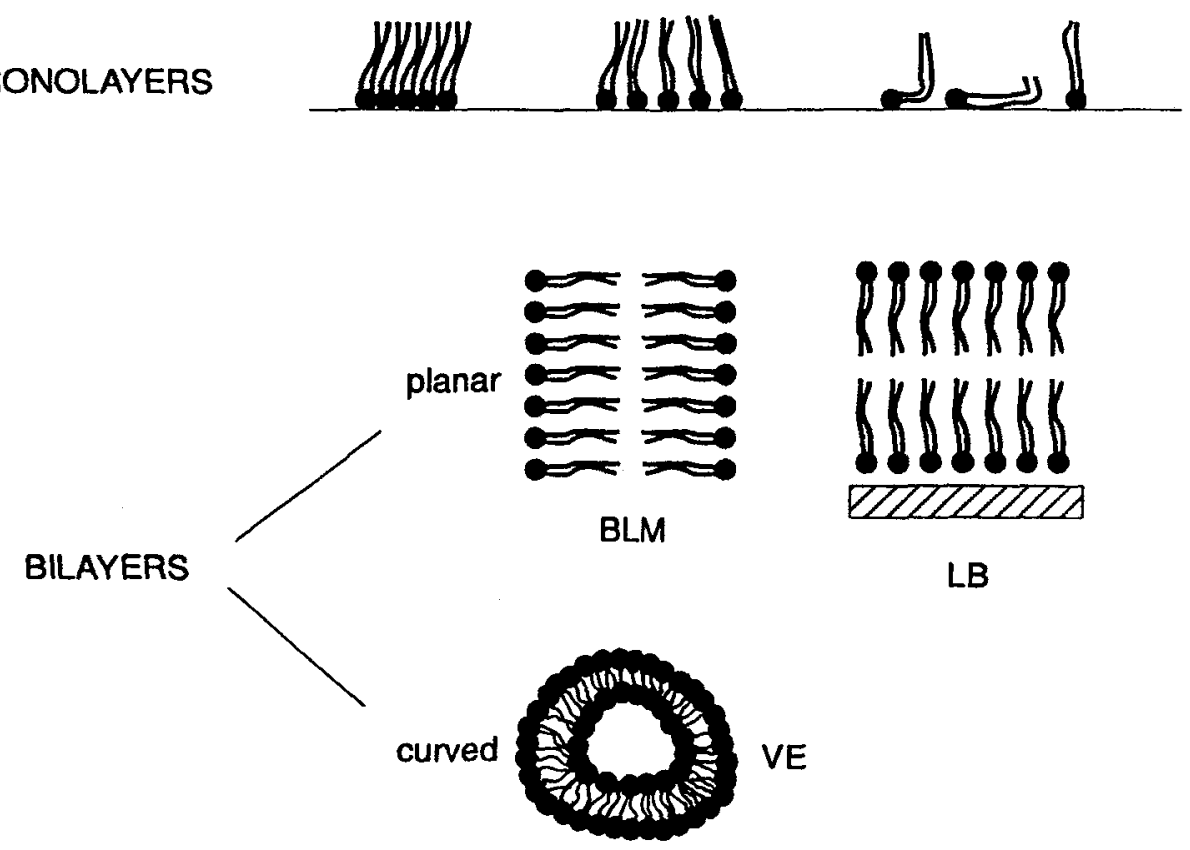

Figure 1. Schematic representation of model systems of natural membranes. 
They were monolayers at water-air interface, flat bilayers such as Langmuir-Blodgettt films (LB) and black lipid membranes (BLM) or closed bilayers as vesicles.

The results obtained for each mimetic membrane system investigated are shown separately.

\section{MONOLAYERS AT LIQUID-AIR INTERFACE}

Monolayers at the liquid-air or liquid-liquid interface are the most typical representations of the bidimensional state and they may be characterized either from a thermodynamic point of view or from a molecular standpoint. Monolayers may be studied adapting spectroscopic techniques used for bulk phases, such as IR or fluorescence emission, or using methodologies peculiar to interface science [5].

The results shown here are relative to low and high molecular weight compounds: the former ones can adequately represent the lipidic portion of membranes, while the latter ones have been used as models of the proteic part.

The investigation of monolayers of amphiphilic compounds alone and in mixtures allowed us to obtain information about the different parameters which influence the molecular distribution of the bidimensional phases and about the energies involved.

If we consider that biological membranes are complex systems constituted by more than one component, it is evident that also the two-dimensional model system has to be composed by several components to be representative. For this reason we have studied monolayers of binary systems composed, for instance, by a lipidic component and polypeptide [13] or by two polypeptides [14] as model of protein mixtures in biological membranes or by two lipidic compounds [15].

In particular figure $2 a$ shows the spreading isotherms of P $\gamma \mathrm{MG}$ and PLA at $25^{\circ} \mathrm{C}$.
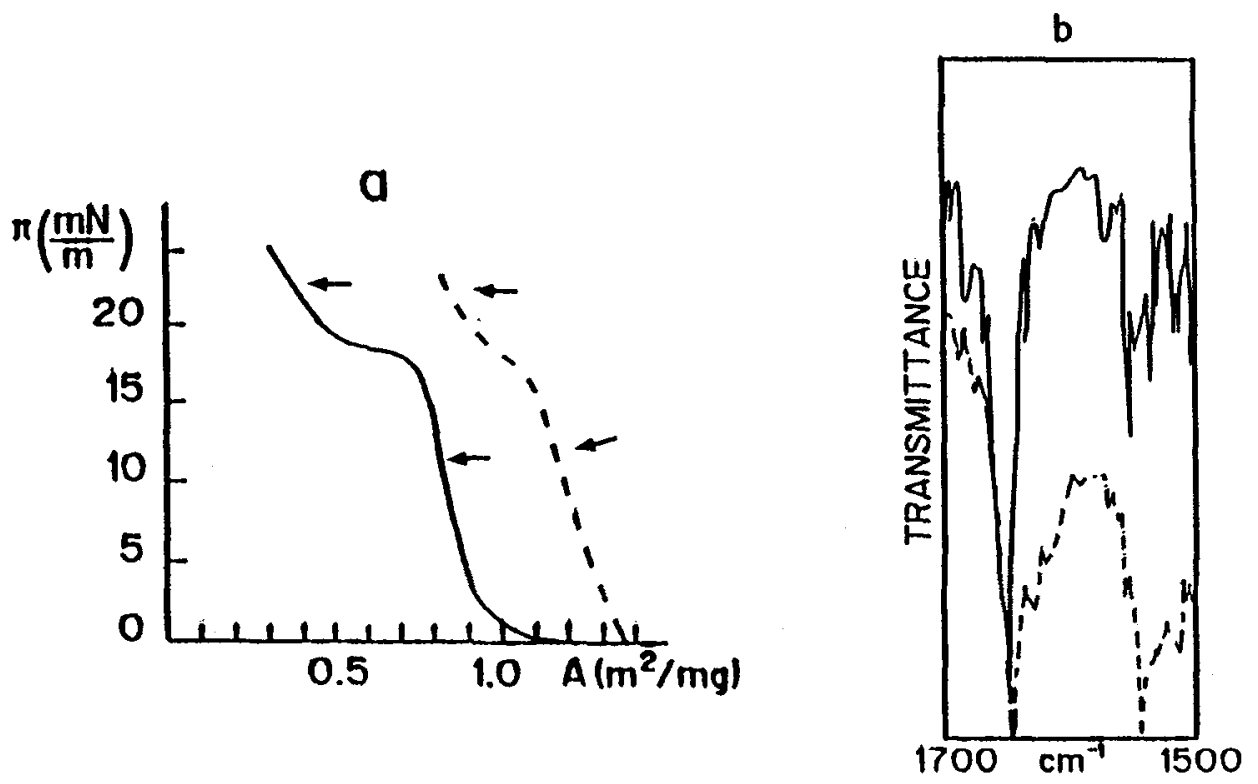

Figure 2. (a) Spreading isotherms at $25^{\circ} \mathrm{C}$ for - P $\gamma M G ;---P L A$.

(b) MIR spectra of - PyMG; - -PLA.

In the figure the arrows show the surface pressure at which the film was transferred from liquid to solid support for the determination of the thickness as well as for MIR spectra.

The two isotherms are shifted with respect to each other but maintain the same shape. Such behavior was due to the different length of the side chains, that is to say it was due to the different chemical 
structure of the amphiphilic molecules. The curves also exhibited a discontinuity which was ascribed to a peculiar type of collapse mechanism, in which the system showed a transition from a mono to a bilayer and this is typical of $\alpha$-helices molecules [16]. The presence of such structures at the liquid-air interface and the mechanism of collapse were confirmed by the values of thickness of the film transferred onto solid supports before and after the discontinuity which were found to be 10 and $19 \AA$ for PyMG; 5 and $10 \AA$ for PLA. Further evidence was obtained from MIR spectra (fig.2b) in which the two typical peaks characteristic of $\alpha$-helices at 1650 and $1550 \mathrm{~cm}^{-1}$ were found; $\alpha$-helices at liquid interfaces are characterized by high rigidity and prevailing interaction among the monomeric units. Identical spectra were obtained before and after the discontinuity, this excluded the possibility of a bidimensional phase transition such as the alfa-beta transition of the polypeptide [17]. The presence of $\alpha$-helices forms was also shown by the comparison of the experimental isotherms with the theoretical ones proposed in Huggins' theory [18]. This approach, commonly used in statistical thermodynamics [19], is an extension of the theory of Flory-Huggins for polymer solutions to interfacial systems. Fitting the experimental data with the Huggins' equation, it was possible to deduce the relevant parameters concerning the macromolecular distribution and the conformation at the interface.

\section{TABLE 1}

Huggins parameters at $298 \mathrm{~K}$ for PyMG monolayers.

$\begin{array}{rcccr} & \pi_{\mathrm{L}}{ }^{(\mathrm{a})} & \pi_{\mathrm{H}}{ }^{(\mathrm{b})} & \pi_{\mathrm{L}}{ }^{(\mathrm{a})} & \pi_{\mathrm{H}^{(b)}} \\ \varphi & -3.9 & -14.3 & -3.2 & -24.5 \\ \mathrm{~K} & 0.51 & 0.41 & 0.48 & 0.29 \\ \mathrm{~K}^{\prime} & 3.80 & 5.80 & 4.40 & 9.80 \\ \varepsilon_{\Delta} & 600 & 3700 & 4000 & 16500\end{array}$

(a) $\pi \leq 3 \mathrm{mN} / \mathrm{m}$

(b) $3 \mathrm{mN} / \mathrm{m} \leq \pi \leq 7 \mathrm{mN} / \mathrm{m}$

The obtained results are shown in table 1 , where $\varphi$ represents the Gibbs free surface energy, $\mathrm{K}$ represents the equilibrium constant between polymer-polymer, polymer-substrate and substratesubstrate contacts and $\varepsilon_{\Delta}$ values are correlated to contact energies per unit length.

$\varphi$ values were always negative confirming that the monolayers were stable, most of all at high surface pressure values. $\mathrm{K}$ values less than 1 indicated a greater probability of polymer-polymer contacts than polymer-solvent. $\varepsilon_{\Delta}$ values were always positive, indicating that attractive energies between polymer segments were prevalent.

All the above findings allowed us to state that the polymer conformation at the interface was rigid with strong interactions between the polymeric segments and negligible interactions with the subphase for both polymers.

Mixtures of the two polymers at the water-air interface were also studied as a simple example of protein mixtures in membranes. Figure 3 reports the parameters extracted from the analysis of the spreading isotherms, that is, molecular areas at $10 \mathrm{mN} / \mathrm{m}$ (A) (a), surface compressional moduli $\left(\mathrm{Cs}^{-1}\right)$ (b) and collapse pressure $\left(\pi_{\mathrm{c}}\right)$ (c) as a function of the monolayer composition. The deviation from ideality of the molecular areas as a function of the mixture composition was a clear indication about the miscibility of the two components at the liquid-air interface. This finding was confirmed by applying the bidimensional phase rule [20] since $\pi_{c}$ varied with the composition of the mixtures. Further 
information about the miscibility between P $\gamma$ MG and PLA were deduced by computing the surface free energy of mixing $\Delta \mathrm{G}_{\text {mix }}$, integrating the $\pi$-A isotherms [21] up to a $\pi$ lower than the discontinuity surface pressure (figure $3 \mathrm{~d}$ ).

$\Delta \mathrm{G}_{\text {mix }}$ showed always negative values meaning that the mixtures were thermodynamically more stable than the pure components and that attractive interactions between the components were prevailing.

The MIR spectra of the two mixtures indicated that $\alpha$-helix configuration was preserved in the mixture (fig. 3e).

We estimated the attractive energies between the components in the condensed phase applying Joos theory [16c, 22] which considers the collapse pressure as an equilibrium pressure between a bidimensional and a tridimensional phase.

a

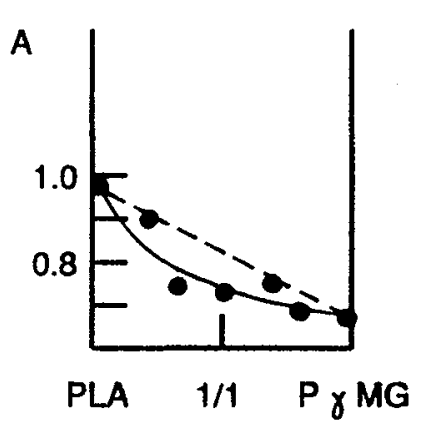

b

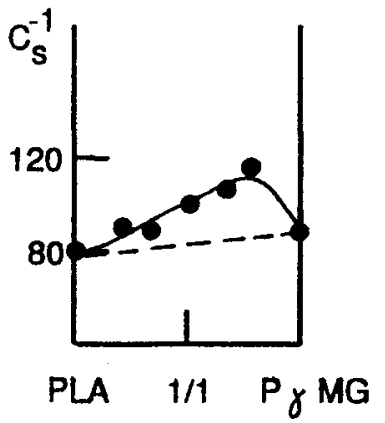

C

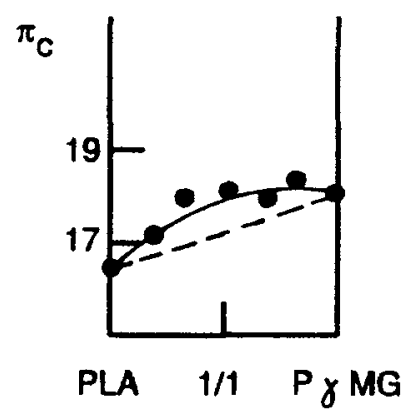

e
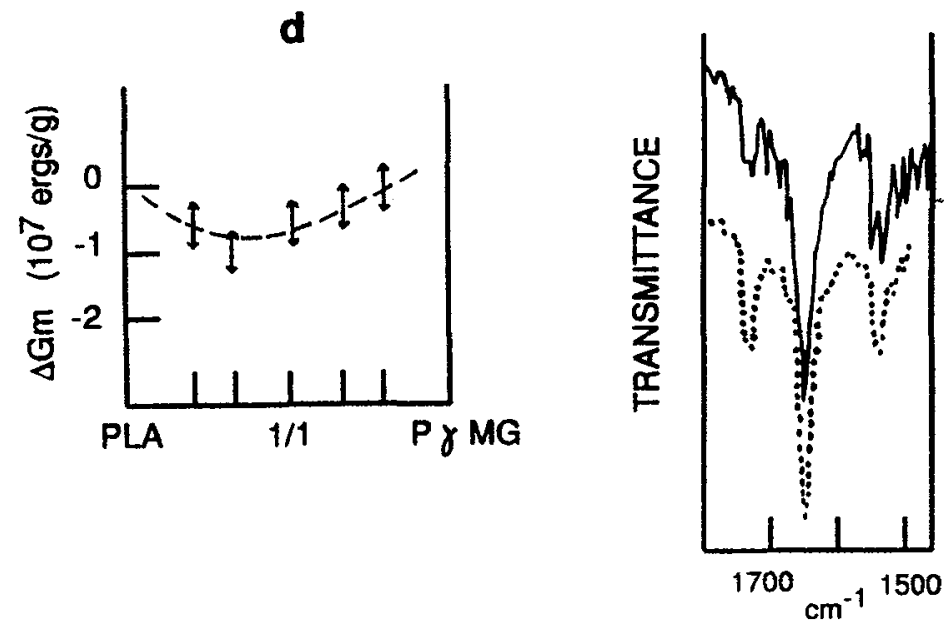

Figure 3. PLA/P $\gamma M G$ system. (a) Surface areas $\left[\mathrm{m}^{2} / \mathrm{mg}\right]$ vs molar ratios between monomeric units at $25{ }^{\circ} \mathrm{C}$ and $10 \mathrm{mN} / \mathrm{m}$. (b) Surface compressional modulus $\mathrm{C}_{\mathrm{s}}^{-1}=\mathrm{A}(\partial \pi / \partial \mathrm{A})_{\mathrm{T}}[\mathrm{mN} / \mathrm{m}]$ vs molar ratios at $25{ }^{\circ} \mathrm{C}$. (c) Collapse pressure $[\mathrm{mN} / \mathrm{m}]$ vs molar ratio at $25{ }^{\circ} \mathrm{C}$. (d) Surface free energy of mixing against molar ratios. Arrows correspond to the $15-30{ }^{\circ} \mathrm{C}$ temperature range. (e) MIR spectra

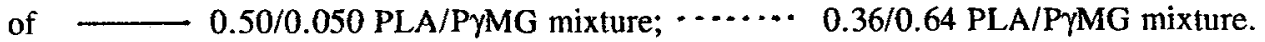

With this treatment we found rather low interaction energies, namely of the order of $0.1 \mathrm{cal} / \mathrm{mole}$.

The reported example indicated the possibility of obtaining the interphasal distribution of polymeric substances in agreement with what previously found for different kinds of macromolecules 
[18b] and confirmed previous findings [23], that is to say that bidimensional miscibility between non ionic components is almost exclusively related to the interactions between the hydrophobic chains, thus depending on their mutual disposition. For what regards the two above discussed polypeptides the analogy in their chemical structures and in the interphasal arrangement were the relevant parameters for miscibility.

\section{STRUCTURE - PROPERTIES RELATIONSHIP IN DIFFERENT MODEL SYSTEMS}

The second step we wanted to pursue is the comparison among different model systems, In this way it is possible to estimate the representability of the models as well as to define the optimal combination of molecular structures and interfacial distributions for each system. In turn this leads to the accomplishment of mimetic membranes for every specific model.

For this reason we studied both phospholipid "precursors" such as 1-monooleoyl-glycerol and 1monostearoyl-glycerol and common phospholipids, such as dioleoylphosphatidylcholine and sphingolipids, which are natural membrane compounds [24].

\section{a}
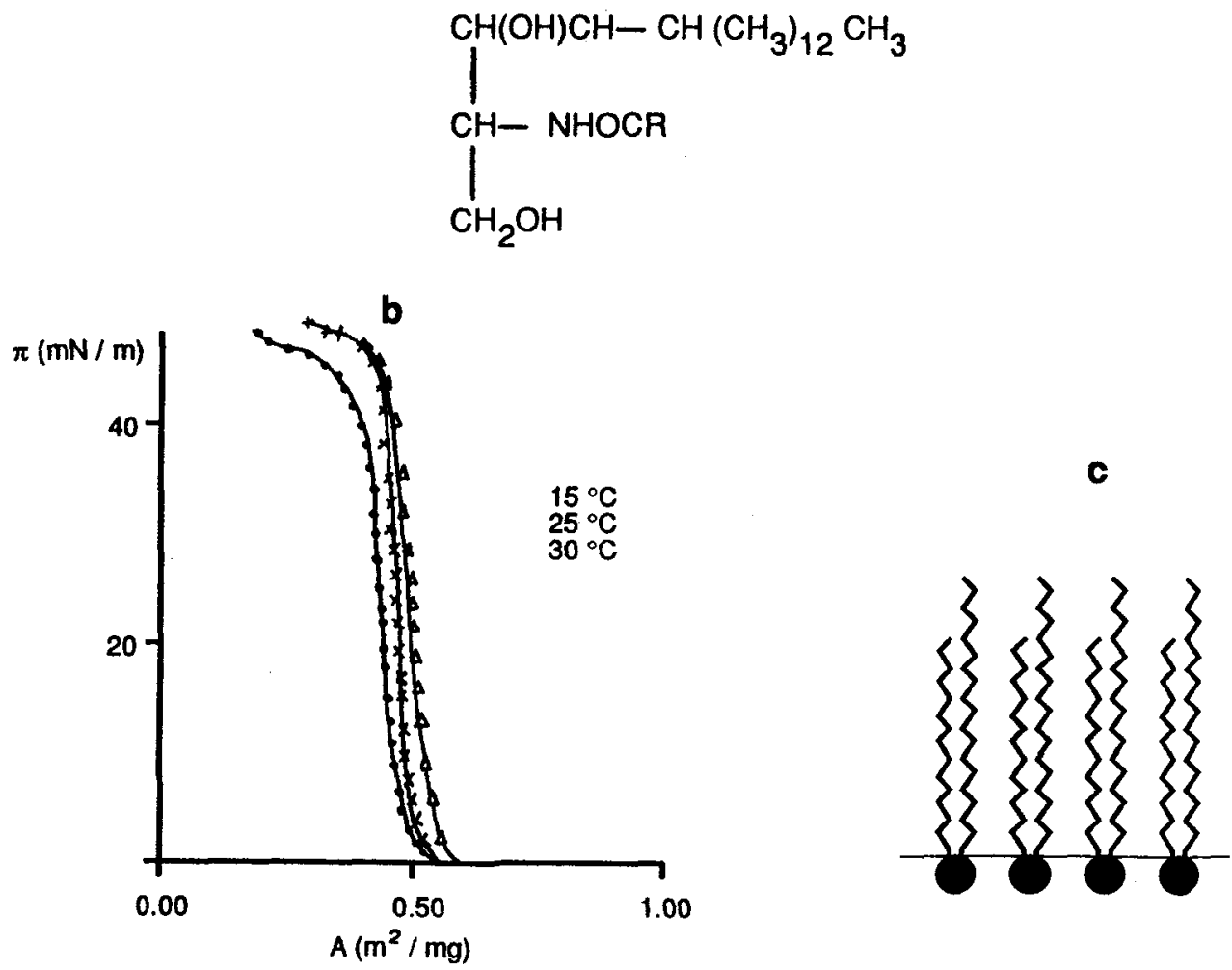

Figure 4. (a) Spreading isotherms of CER at water-air interface. (b) CER chemical structure. (c) Schematic representation of CER distribution at the interface.

As a general example, we illustrate the study performed on ceramide (CER). Ceramide is a common 
prototype of sphingolipids and bears two aliphatic chains with a different number of carbon atoms (fig.4).

Monolayers of pure ceramide were studied at water-air interface on a subphase containing $\mathrm{NaCl} 0.1 \mathrm{M}$ solutions and at different temperatures.

The experimental spreading isotherms of CER in the temperature range of $15^{\circ}-30^{\circ} \mathrm{C}$ are reported in figure $4 \mathrm{a}$ together with a simplified scheme of interfacial distribution of the molecule (fig. $4 \mathrm{c}$ ).

The most important parameters of the monolayers such as: the limiting area, $A_{0}$, the surface compressional modulus, $\mathrm{C}_{\mathrm{s}}^{-1}$, and the equation of state in the linear part of isotherm are collected in table 2. These showed that CER gave stable monolayers with characteristic features of the liquid condensed phase with relatively high hydrophobic interactions between the chains.

\section{TABLE 2}

\section{Parameters for CER monolayers.}

$\begin{array}{cccc}\text { Temperature }\left({ }^{\circ} \mathrm{C}\right) & \begin{array}{c}\text { Bidimensional state } \\ \text { equation }\end{array} & \mathrm{A}_{0}\left(\AA^{2} / \text { molecule }\right) & \mathrm{C}_{\mathrm{s}}^{-1} \max (\mathrm{mN} / \mathrm{m}) \\ & & & \\ 15 & \pi=133.9-377.5 \mathrm{~A} & 50.5 & 164.7 \\ 25 & \pi=124.1-187.5 \mathrm{~A} & 55.6 & 187.0 \\ 30 & \pi=133.9-233.6 \mathrm{~A} & 50.5 & 270.0\end{array}$

CER monolayer was easily transferred onto a solid support and its thickness was measured ellipsometrically. We obtained a thickness of $25 \AA$ for one layer, such a value confirmed the orientation of the molecule depicted in figure $4 \mathrm{c}$ with the chains almost normal to the interfacial plane. LB films were obtained transferring two layers of ceramide in a tail-to-tail architecture, the trasfer was reproducible and ellipsometric measurements provided a value for the thickness of $52 \AA$ [24].

Since the hydrocarbon chains of the ceramide molecule differed at least by 4 carbon atoms, this value of thickness for the bilayer suggests interdigitation of the chains. This phenomenon was already found for similar substances in other two-dimensional systems [25].

In conclusion we may say that CER gives very stable monlayers and LB bilayers, whereas we cannot obtain stable BLM or vesicle. Therefore we can deduce that the high rigidity of the monolayer and the closely interacting hydrocarbon chains, typical of condensed monolayers, prevent formation of BLM or vesicles. On the contrary LB multilayers, which are pseudo-solid supramolecular structure, may be obtained only from monolayers in the condensed phase as was previously stated [26].

BLM and vesicles as mimetic systems may be only obtained fluidificating the hydrocarbon moiety. We can reach this goal in two different methods: raising the temperature [27] or, as in natural occuring membranes, mixing CER with substances that give monolayers with highly expanded phases [2,24].

Following tha latter way, we studied two different mixtures: ceramide/1-monooleoyl-glycerol ( which is a "model" compound) and ceramide and the natural occuring dioleoylphosphatidylcholine (DOPC).

Both these compounds form monolayers mostly in the expanded phase $[2,15]$ because they possess a double bond in their hydrocarbon chains, a factor which is well known to induce expansion of the monolayer [28].

Molecular areas and collapse pressures obtained from the spreading isotherms as a function of monolayer composition are reported in figure 5. It is readly evident from the figure that in both cases we observed bidimensional miscibility.

Moreover, positive deviations from ideality indicated that the compounds in the bidimensional state 
experience mainly repulsive interactions and that the phase of the mixed monolayer is of the expanded type.

Once stated that either the model, MON, and the natural, DOPC, lipid gave similar results in monolayer, we attempted to prepare BLM an vesicles with the previously described mixtures.

A
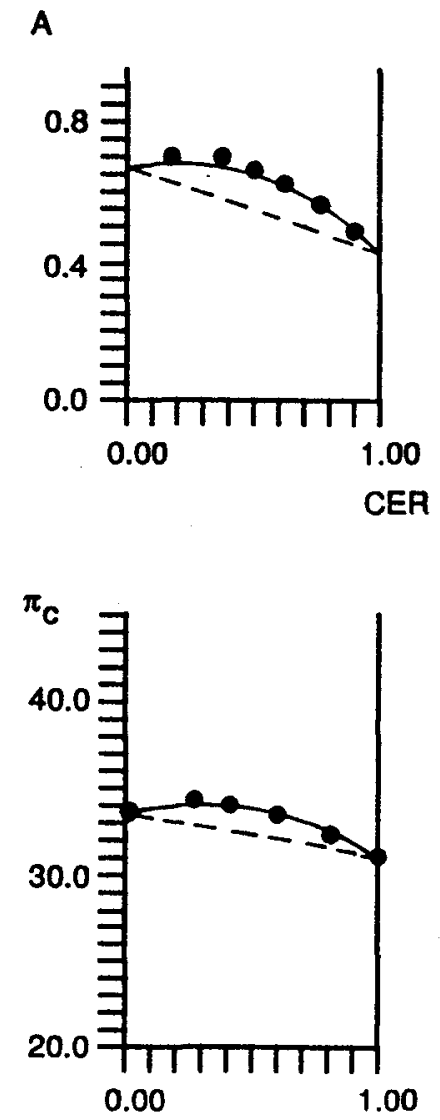

$\bar{B}$
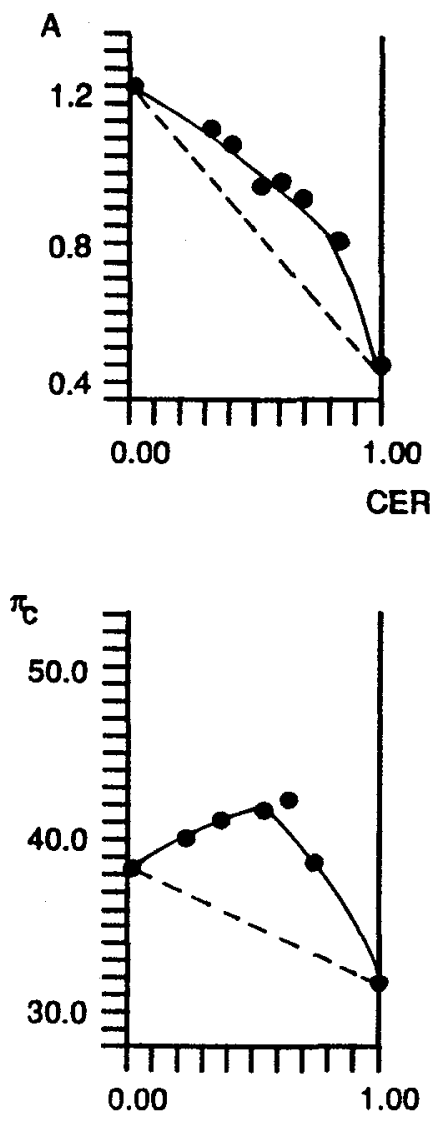

CER

Figure 5. Behaviour of surface areas $\left[\mathrm{m}^{2} / \mathrm{mg}\right]$ (top) and collapse pressures $[\mathrm{mN} / \mathrm{m}]$ (bottom) as a function of weight fraction. (A) CER/MON; (B) CER/DOPC.

In particular it was possible to prepare stable and reproducible BLM from CER/MON mixtures using squalene as dispersing solvent.

The electrical resistance and capacitance of CER/MON black lipid membranes were measured in presence of $\mathrm{NaCl} 0.1 \mathrm{M}$ solutions and the experimental data are reported in table 3, where it is shown that the capacitance of membranes formed by the CER/MON mixture is lower than for the BLM of pure 1-monooleoyl-glycerol.

Since capacitance values are proportional to the reciprocal of the thickness of the membranes, we may conclude that MON/CER mixture formed BLM with higher thickness. This was due to the condensating effect of the ceramide which was reflected in a vertical ordering of the chain in a closely packed distribution. Further characterization of this BLM system was previously reported $[2,24]$.

For what concerns the system CER/DOPC it was possible to obtain stable vesicles after sonication of mixtures of the two components in phosphate buffer. 
Scanning electron micrographs of these vesicles are reported in a previous paper [29] and showed the existance of vesicles with an average diameter of $250 \AA$.

\section{TABLE $\quad 3$}

\section{Electrical parameters for BLM of MON and MON/CER.}

$\begin{array}{ccc}\text { CER/MON } & \text { Capacitance }\left(\mu \mathrm{F} / \mathrm{cm}^{2}\right) & \text { Resistance }\left(\Omega \cdot \mathrm{cm}^{2}\right) \\ 1 / 1 & 0.61 & 10^{6} \\ 1 / 3 & 0.64 & 10^{7} \\ 1 / 3 & 0.63 & 10^{6} \\ 1 / 5 & 0.64 & 10^{6} \\ \text { MON } & 0.74 & 10^{7}\end{array}$

We also checked that using only CER we could not obtain any vesicle structure [29], as shown by the absence in this system of the osmotic shock phenomenon $[29,30]$.

Finally the mobility of the chains in the lipidic double-layer of the CER/DOPC vesicles, was determined inserting an electron spin resonance probe in the bilayer, in particular, doxyl-stearic acids labelled in different positions of the chain were used as ESR probe [29].

The comparison of the same compound, or mixtures of compounds, in structurally different models such as: monolayers, LB films, BLM and vesicles induced us to transfer the information obtained for one system to the other, and to formulate general expectations on the structure and functionality from the interfacial behaviour of its components.

At this stage our interest focused on the modelling of processes occurring in natural membranes and on the design of membranes on the basis of the required properties.

\section{PHOTOPROCESS IN MIMETIC MEMBRANES}

One of the processes commonly encountered in biological systems is the transfer of energy or charge across a membrane, or at a membrane interface.

In particular, electron flow and generation of charge separation in membrane systems is one of the key question in understanding the energy capture machinery of biology.

Much effort is currently devoted to understand these processes at a molecular level, in terms of distances between the reactants, their relative distribution and mobility.

For this reason we started a systematic investigation of photoinduced electron transfer (P.E.T) in mimetic membranes.

With the term P.E.T. we mean the transfer of one electron from the excited donor molecule to the ground state acceptor. In solution, P.E.T. occurs via molecular collisions between the freely diffusing reactants and it is always followed by fast reverse electron transfer which reduces its efficiency.

To mimic biochemical function is, instead, necessary to work in confined system in the attempt to accomplish charge separation and to clarify the mechanism.

Among the variety of confined organized systems, monolayers are especially attractive for several reasons: first of all the immobilization of the reactants at controlled distances is elegantly accomplished. Secondly, one of the reactants may be diluted in a lipid matrix, as in natural system, whereas the other partner is solubilized in the aqueous environment. 
A schematic picture of P.E.T. processes at monolayer-water interface is reported in figure 6 . The monolayer is composed of a matrix molecule which reproduces the lipid portion of the membrane, in this case dipalmitoylphosphatidic acid (DPPA), in which an appropriate donor is diluted. The acceptor, in this case methylviologen, is solubilized in the aqueous phase.

The donor, excited with light of the appropriate wavelenght, may return to its ground state following the deactivation paths shown in figure 6, that is to say either with emission of light or, if the acceptor is present in the system, transferring one electron to the redox partner.

These two processes are competitive and P.E.T. is evidenced clearly by a decrease in fluorescence emission in the presence of the acceptor.

Before studying the P.E.T. reaction, we investigated the process of the acceptor adsorption at monolayer-water interface obtaining the actual density of $\mathrm{MV}$ at the interface, its orientation and the kinetics of the process [32].
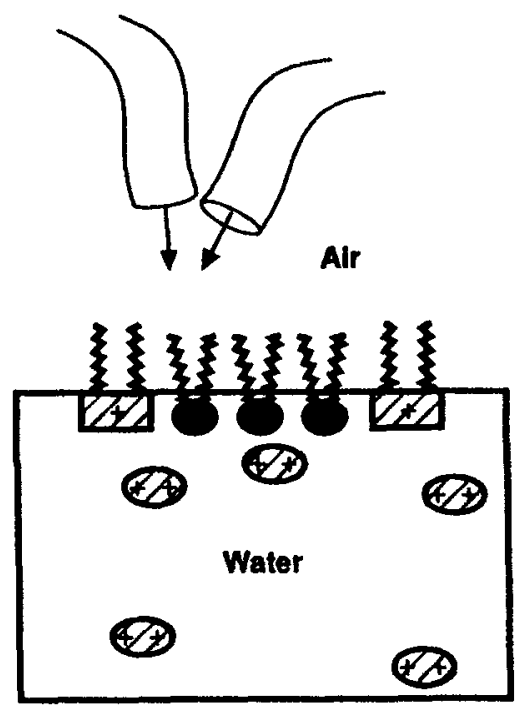

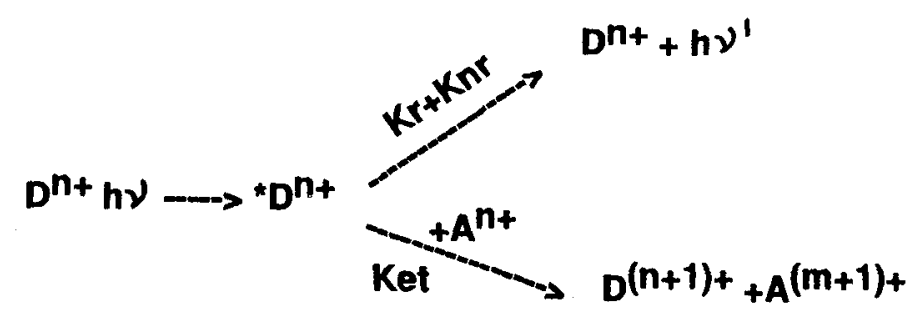

Figure 6. Schematic representation of P.E.T. investigation at monolayer-water interface and possible deactivaction paths of the excited donor.

We also characterized the monolayer constituted by DPPA and the oxocyanine that acted as the donor (fig. 7b). For these studies we used a variety of complementary techniques such as surface pressure, surface potential, reflection and fluorescence measurements [30].

The results indicated that the cyanine dye is diluted as monomer in the DPPA matrix at the optimal molar ratio of $10: 1$, this is shown in figure 7 (a) where the characteristic peak of the monomer OC appears at $370 \mathrm{~nm}$. Moreover the orientation of the cromophore and its distribution at the interface do not vary with monolayer compression.

The acceptor was readly adsorbed at monolayer-water interface, as shown by the presence of a band at $280 \mathrm{~nm}$ in the reflection spectrum (fig. 7a), MV was adsorbed in a flat conformation due to pure electrostatic attractions.

To study P.E.T. mechanism we performed fluorescence quenching experiments on the monolayer system with different amounts of quencher (MV) in the subphase.

Surface pressure and fluorescence intensity at the maximum of cyanine emission $(\lambda=425 \mathrm{mn})$ were measured as a function of compression (both in the presence and in absence of MV). The results are reported in figure $7 \mathrm{~b}$. The mixed monolayer DPPA/OC $(10: 1)$ on water exhibited a strong emission 
even at low surface pressure.

(a)

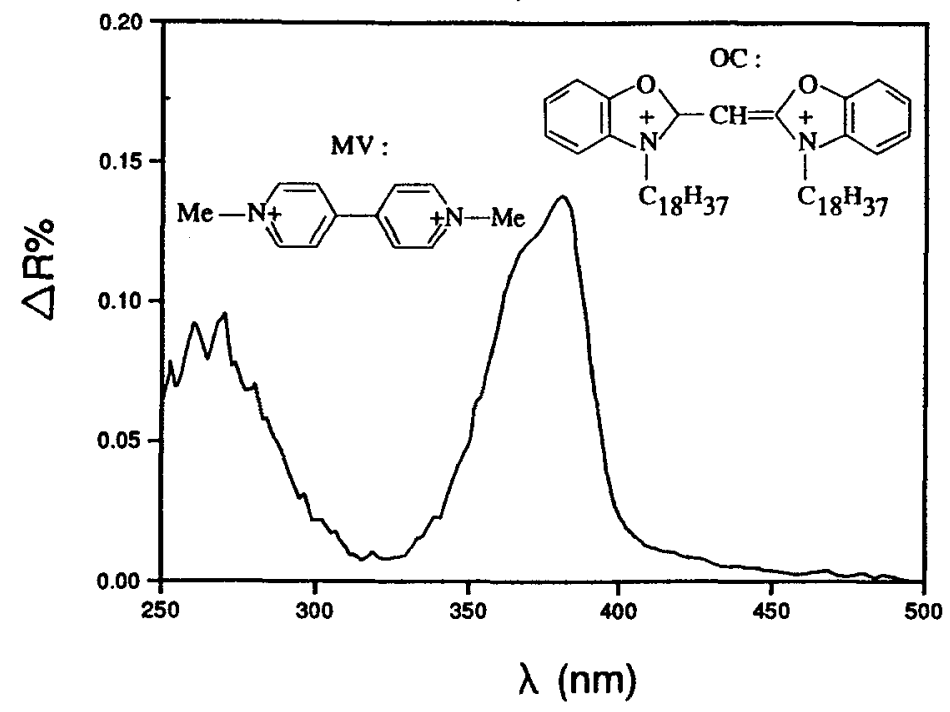

(b)

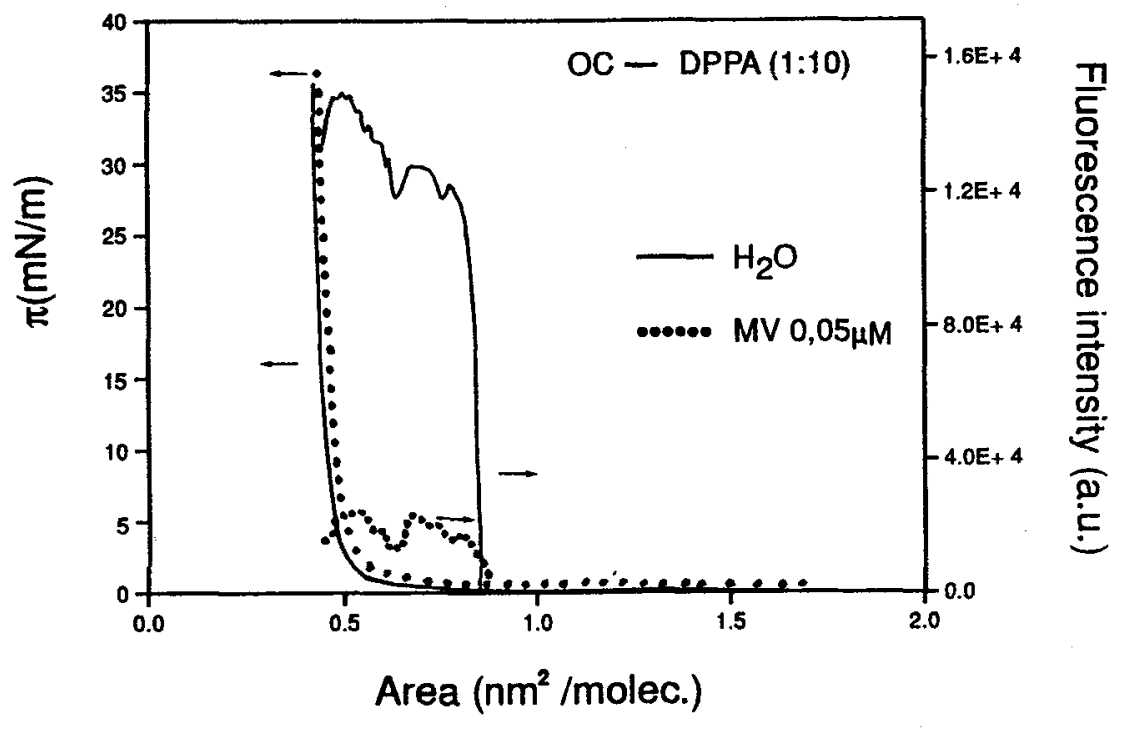

Figure 7. (a) Reflection spectra of a monolayer of DPPA/OC (10:1 molar ratio), at water-air interface. Subphase composition: MV $10^{-6} \mathrm{M}, \pi=20 \mathrm{mN} / \mathrm{m}$. (b) Fluorescence intensity at $425 \mathrm{~nm}$ $\left(\lambda_{\text {ex }}=365 \mathrm{~nm}\right)$ and surface pressure as a function of molecular areas for DPPA/OC (10:1 molar ratio) monolayer at water-air interface.

A concentration of MV in the subphase as small as $510^{-8} \mathrm{M}$, produced a sudden decrease in fluorescence intensity. Emission and excitation spectra showed no evident changes in shape and we ascribed the decrease in intensity to the transfer of one electron between the redox couple. 
In analogy with P.E.T. studies in solution we measured fluorescence intensity at constant molecular areas, and thus at constant donor concentration, for increasing amounts of MV in solution.

As in bulk solution we performed a Stern-Volmer analysis of the data plotting Io/I, remarkably $50 \%$ quenching is obtained for every surface area at the same MV concentration.

The dependence of $\mathrm{I}_{\mathrm{o}} / \mathrm{I}$ from concentration is linear in the condensed phases of the monolayer, whereas for low concentration of donor (high molecular areas) the upward curvature of the plot indicated either a contribution due to static quenching or an additional mechanism which is not purely diffusive.

The quenching efficiency parameter, represented by the Stern-Volmer constant Ksv, was extracted from the plot and it was found to be several order of magnitude higher than the one for the same process in bulk solution [31].

We can describe the process as composed by:

-diffusion of the acceptor towards the interface from bulk solution;

-adsorption at monolayer-water interface;

-electron transfer reaction (P.E.T.).

Moreover, it was found that this last step occurs with a bidimensional diffusion mechanism at least in the condensed phase [32].

The interpretation of the quenching data according to a hard disk model gave a value for the critical radius of $120 \AA$, this represented the distance at which every collision results in an effective transfer of one electron.

This anomalous large value was confirmed by similar experiments on Langmuir-Blodgett films. The same DPPA/OC 10:1 mixed monolayer was transferred on quartz slide, and immersed in a cell containing a solution of the acceptor, MV.

The results showed that in this case the Ksv was only slightly smaller than at monolayer-water interface and that the data were nicely fitted with a hard disk model with a value for the critical radius of $130 \AA$.

These experiments showed how the efficiency of the electron transfer process increases dramatically whenever a system with restricted space and defined orientation of the reactants is used.

\section{MASS TRANSPORT ACROSS A MIMETIC MEMBRANE}

The other outstanding feature of biological membranes is their possibility to selectively transport ions.
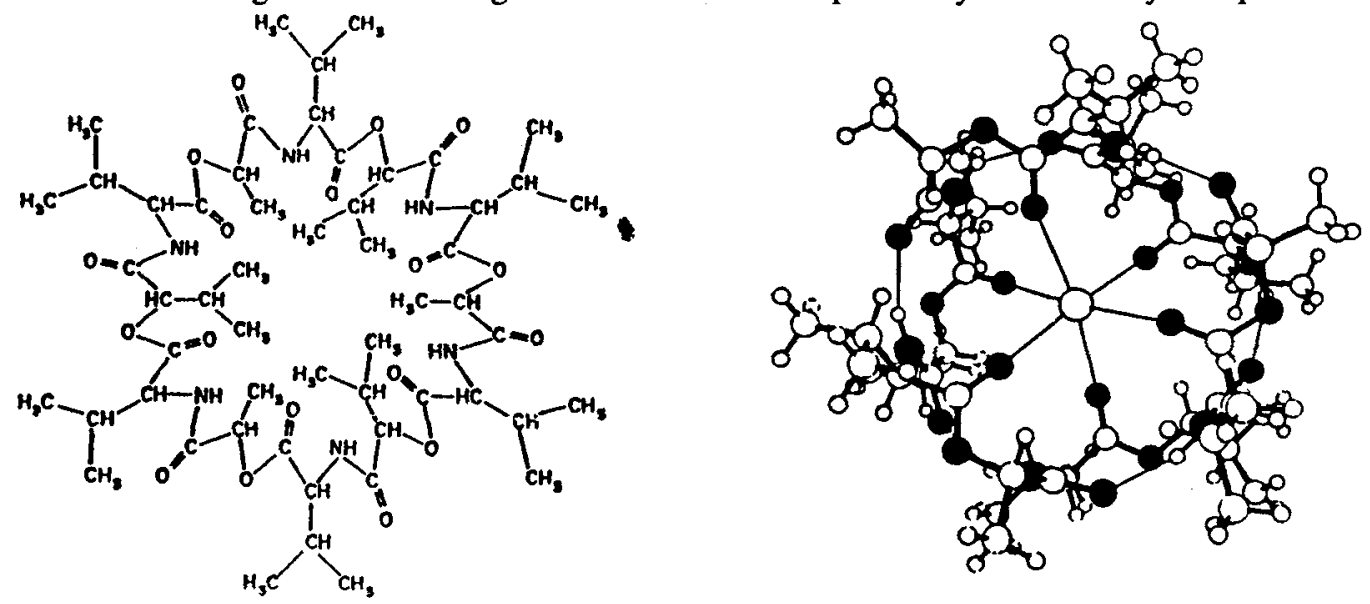

Figure 8 Schematic representation of the chemical structure of : a) valinomycin; b) valinomycin with inserted $\mathrm{K}^{+}$.

There are two fundamental mechanisms commonly recognized to explain this process, namely channel 
formation or ion carrier mechanism [33].

We have chosen to study this process investigating in more detail the second type of mechanism. The process may be represented as the diffusion of typical substances, usually of cyclic shape, across the double layer.

These compounds have an external surface constituted by hydrophobic chains and an internal hydrophilic cavity where ions are entrapped.

With this in mind, we built a mimetic membrane inserting an ion-carrier in a lipidic bilayer. In particular we chose a compound which selectively bind $\mathrm{K}^{+}$ions, valinomycin, whose chemical structure with and without potassium ions is reported in figure 8. monolayers.

We first studied monolayers of pure valinomycin, VAL/SA [34] and VAL/MS [35] mixed

$A\left(m^{2} / m g\right)$
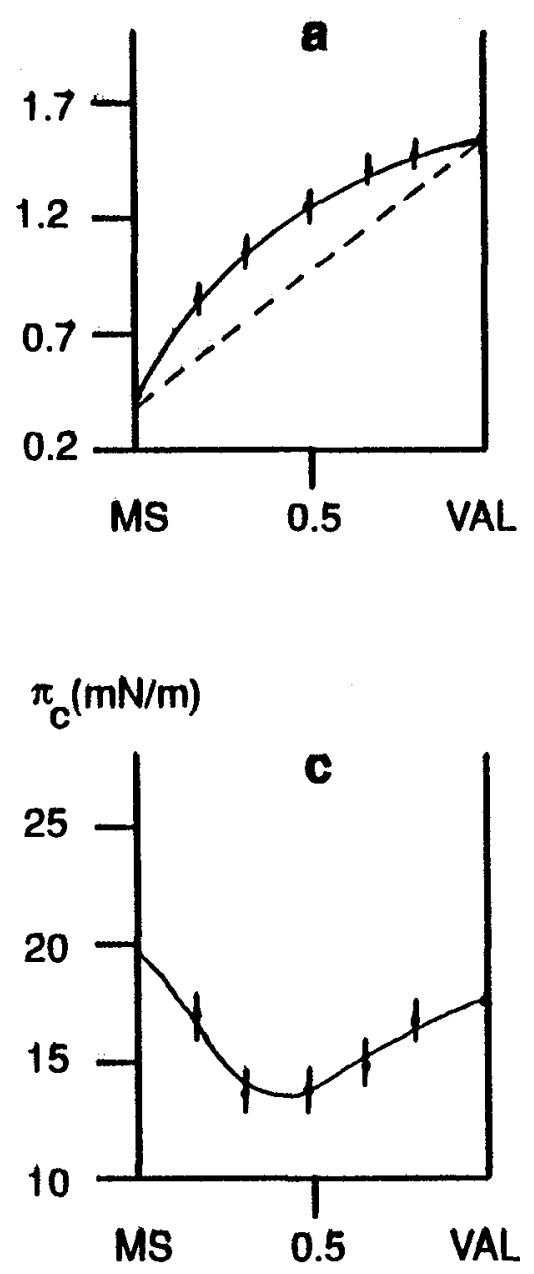

$$
\mathrm{C}_{\mathrm{s}}^{-1}(\mathrm{mN} / \mathrm{m})
$$

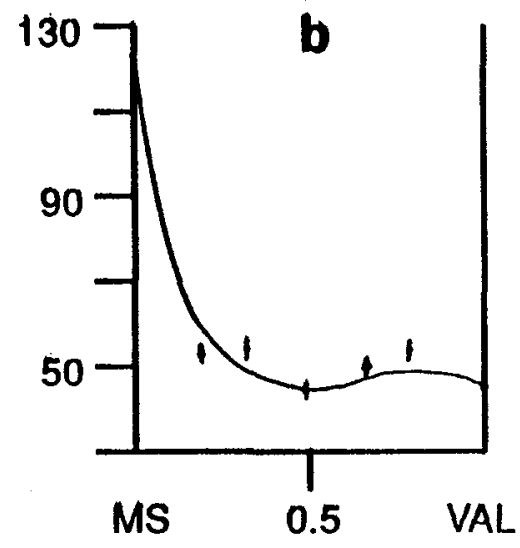

$\Delta$ Gmix (Joule/g)

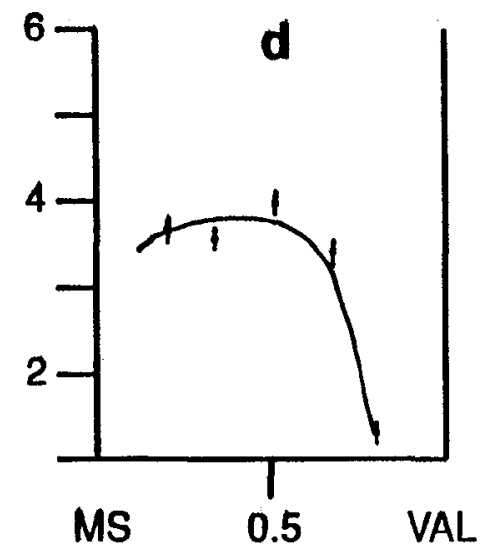

Figure 9. VAL/MS mixture at $20^{\circ} \mathrm{C}$. Weight fraction dependence on: (a) surface area [ $\mathrm{m}^{2} / \mathrm{mg}$ ], (b) surface compressional modulus $[\mathrm{mN} / \mathrm{m}]$, (c) collapse pressure $[\mathrm{mN} / \mathrm{m}]$, (d) surface free energy of mixing $[\mathrm{J} / \mathrm{g}]$. 
We chose to study mixture of VAL instead of pure VAL for a number of reasons. Firstly because it was demonstrated that VAL monolayers show expanded phases and therefore may be hardly transferred on solid supports as LB films. Secondly it was previously demonstrated [36] that the pure valinomycin films do not complex $\mathrm{K}^{+}$. Moreover mixtures of lipids and carrier are a more representative model of natural membranes.

In figure 9 we report the molecular parameters obtained from the spreading isotherms for the binary system VAL/MS. From the results, we can conclude that the two substances were miscible in bidimensional state as confirmed by the positive deviations from ideality of surface areas and from variation of the collapse pressure with molar ratio.

Our next concern was to check that potassium ions were able to migrate from the aqueous subphase to the monolayer containing valinomycin.

The question of $\mathrm{K}^{+} / \mathrm{VAL}$ interactions was addressed collecting ESCA (Electron Spectroscopy for Chemical Analysis) and FT-IR/ATR spectra of the mixed film $[34,35]$ tranferred from a $\mathrm{KCl}$ subphase. The ESCA spectra of VAL/SA evidenced a peak due to the $\mathrm{K}^{+}$ions in the complex at $292.4 \mathrm{eV}$, whereas a separate experiment indicated that the contribution of $\mathrm{K}^{+}$due to the salt form $(\mathrm{KCl})$ shows a binding energy of $293.6 \mathrm{eV}$.

This latter peak was probably deriving from the small amount of $\mathrm{KCl}$ solution trapped between the film and the support.

FT-IR/ATR spectra were performed on germanium slides where three layers of an equimolecular mixture VAL/SA were transferred.

Two peaks were present in the spectra when the LB film were obtained transferring from pure water. These peaks corresponded to the stretching of amidic and esteric $\mathrm{C}=\mathrm{O}$ groups.

If the transfer was performed using $\mathrm{KCl}$ subphase, the two bands were shifted due to the specific interactions of the hydrophilic groups of the inner cavity of VAL with the $\mathrm{K}^{+}$ions $[35,36]$.

Since we demonstrated that the VAL mixture monolayers could bind $\mathrm{K}^{+}$ions from the subphase, we obtained an ion selective membrane transferring the monolayers on porous support by means of the LB technique using the apparatus and the procedure previously described [12].

Transport of ions across the membrane was determined measuring its electrical resistance with the experimental apparatus described in a previous paper [39]. The value of resistance across the membrane are reported in table 4.

\section{TABLE 4}

\section{Resistance values across the mimetic membrane}

Concentration

$0.001 \mathrm{M}$

$0.01 \mathrm{M}$
VAL/MS

2 layers

$\mathrm{KCl}: \quad 140 \mathrm{k} \Omega$

$\mathrm{NaCl}: \quad 499 \mathrm{k} \Omega$

$\Delta=-72 \%$

$\mathrm{KCl}: \quad 34 \mathrm{k} \Omega$

$\mathrm{NaCl}: \quad 136 \mathrm{k} \Omega$

$\Delta=-75 \%$
VAL/MS

70 layers

$\mathrm{KCl}: \quad 20 \mathrm{k} \Omega$

$\mathrm{NaCl}: \quad 34 \mathrm{~kW}$

$\Delta=-41 \%$

$\mathrm{KCl}: \quad 4 \mathrm{k} \Omega$

$\mathrm{NaCl}: \quad 34 \mathrm{k} \Omega$

$\Delta=-88 \%$

The results showed a remarkable increase in electrical conductivity when $\mathrm{K}^{+}$ions were present in solution for the 1:1 mixture of VAL/MS. 
This was not the case if other electrolytes, such as $\mathrm{NaCl}$, were present in solution or if the membrane was composed of VAL and lipids other than MS.

These results showed that it was possible to obtain in this way membranes selective to specific ions.

\section{CONCLUSIONS}

The above experimental results suggest the following main conclusions.

1) Two-dimensional systems, and in particular mono and multilayers, may be succesfully used as simple but representative models of natural membranes.

2) The interfacial distribution and the interaction of the components of membranes, such as lipids and polypeptides, are obtained from investigation of their monolayer properties.

3) The comparison among structurally different model systems allows the definiton of the structural bidimensional features which characterize the formation and stability of the model systems.

4) Biophysical processes such as the transfer of charge or energy in membranes may be modelled and investigated in mono and multilayers.

5) A first example of mimetic membrane obtained by means of Langmuir-Blodgett technique for the selective transport of ions, shows that it is possible to realize mimetic membranes reproducing the functions of the natural ones.

\section{ACKNOWLEDGMENTS}

Thanks are due to the Italian CNR (Consiglio Nazionale della Ricerca) and MURST (Ministero dell ${ }^{*}$ Università e della Ricerca Scientifica e Tecnologica). Dr. D. Möbius is gratefully acknowledged for the use of his instrumentation and his kind collaboration. A.G. thanks Eniricerche S.p.A. (Italy) for a fellowship. Thanks are also due to Mr. P. Parri who skillfully prepared the drawings.

\section{REFERENCES}

/1/ Nicholson, G L, Biochim. Biophys. Acta 457 (1976) 57.

12/ Margheri, E, Niccolai, A, Gabrielli, G, and Ferroni, E, Coll. Surf. 53 (1991) 135.

/3/ Sondermann, J, Liebig Ann. Chem., 183 (1971) 749.

/4/ Gabrielli, G, Puggelli, M, Dei, L, and Domini, C, Colloid and Polymer Sci. 266 (1988) 429.

/5/ Adamson, A W, "Physical Chemistry of Surfaces", J. Wiley Publ. New York (1976).

/6/ Baglioni, P, Carlà, M, Dei, L, and Martini, E, J. Phys. Chem. 91 (1987) 1460.

/7/ Mc Cracking, F L, Passaglia, E, Stromberg, R R, and Steimberg, H L, J. Res. 67A (1963) 363.

18/ Lo Nostro, P, and Gabrielli, G, Coll. Surf. 44 (1990) 119.

19/ Mueller, P, Rudin, D O, Titien, and Westoit, W C, Circulation 26 (1962) 1167.

/10/ Grüniger, H., Mobius, D, and Meyer, H, J. Chem. Phys. 79 (1983) 3701. 
/11/ Kuhn, H, in Gerischer, H, and Meyer, H, eds. Light Induced Charge Separation in Biology and Chemistry, Verlag Chemie (1979) p.151.

/12/ Gilardoni, A, Margheri, E, and Gabrielli, G, Coll. Surf. in press.

/13/ a) Dei, L, Baglioni, P, and Gabrielli, G, "Surfactants in Solution" vol. 5, Mittal K.L, Ed. (1989) 979.

b) Gabrielli, G, Gliozzi, A, Sanguineti, A, and D'Agata, A, Coll. Surf. 35 (1989) 261.

c) Baglioni, P, Dei, L, Ferroni, E, and Gabrielli, G, Coll. Surf. 60 (1991)399.

/14/ a) Baglioni, P, Dei, L, Gabrielli, G, Innocenti, F,M, and Niccolai, A, Colloid Polym. Sci. 266 (1988) 783.

b) Puggelli, M, Gabrielli, G, and Domini, C, Progr. Coll. Polym. Sci. 266 (1988) 783.

/15/ a) Bonosi, F, Gabrielli, G, and Margheri, E, Thin Solid Films, 210 (1992) 105.

b) Gabrielli, G, Niccolai, A, and Dei, L, Coll. Polym. Sci. 264 (1986) 972.

/16/ a) Malcom, B R, in "Applied Chemistry at Protein Interfaces" Adv. Chem. Series, 145 (1975) 338 .

b) Loeh, G,L, and Baier, R,E, J. Coll. Interface Sci. 27 (1968) 38.

c) Puggelli, M, Gabrielli, G, and Caminati, G, Coll. Polym Sci. 267 (1989) 65.

/17/ a) Baglioni, P, Gallori, E, Gabrielli, G, and Ferroni, E, J. Coll. Interface Sci. 88 (1982) 221.

b) Baglioni, P, Dei, L, and Gabrielli, G, J. Coll. Interface Sci. 93 (1983) 402.

/18/ a) Huggins M L, Koll. .Z. Polym. 251 (1973) 449.

b) Gabrielli, G, Ferroni, E, and Huggins, M L, Progr.Coll. Polym. Sci. 58 (1975) 201.

/19/ a) Flory, P Y, J. Chem. Phys. 10 (1942) 51.

b) Huggins, M L, J. Phys. Chem. 46 (1942) 151.

/20/ Gaines, G L Jr, "Insoluble Monolayers at Liquid-Gas Interfaces", Interscience Publ. 1966, New York, pp. 281-6.

121/ Goodrich, F C, Proceedings 2nd International Congress Surface Activity, vol. 1, Butterworths, London (1957) p 85.

/22/ Joos, P, Bull. Soc. Chem. Belges 78 (1969) 207; Biochim. Biophys. Acta 183 (1969) 447.

/23/ Gabrielli, G, Puggelli, M, and Baglioni, P, J. Coll. Interface Sci. 86 (1982) 485.

/24/ Gabrielli, G, Adv. Coll. Interface Sci. 34 (1991) 31.

/25/ a) Davis, P J, and Keough, K M W, Biophys. J. 48 (1985) 915.

b) Huang, C and Mason, J T, Biochim. Biophys. Acta 864 (1986) 423.

/26/ Gabrielli, G, Puggelli, M, Ferroni, E, Carubia,G, and Pedocchi, L, Coll. Surf. 41 (1989) 1.

/27/ Bonosi, F, and Gabrielli, G, Coll. Surf. 52 (1991) 277.

128/ Davies, J T, and Rideal, E K, "Interfacial Phenomena", Academic Press, 1963, New York, pag. 234.

/29/ Bonosi, F, Gabrielli, G, Margheri, E, and Martini, G, Langmuir 6 (1990) 1769.

/30/ Caminati, G, Ahuja, R C, and Möbius, D, Progr. Colloid and Surface Sci. in press.

/31/ Caminati, G, Ahuja, R C,and Möbius, D, Thin Solid Film, 210, (1992) 335.

/32/ Caminati, G, Ahuja, R C, and Möbius, D, J. Phys. Chem. accepted for publ.

133/ Gliozzi, A, and Rolandi, R, in "Membranes and Sensory Transduction", Colombetti, G, and Lenci, F, Eds. Plenum Press, (1984) pag. 1-62.

134/ Gabrielli, G, Puggelli, M, and Prelazzi, G, Progr. Colloid Polym. Sci. 84 (1991) 232.

/35/ Gabrielli, G., Puggelli, M, and Gilardoni, A, Progr. Colloid Polym. Sci. 89 (1992) 1.

/36/ Howarth, V A, Petty, M C, Davies, H, and Yarwood, J, Langmuir 5 (1989) 330. 